UDK 339.92(4)

Biblid 0543-3657, 71 (2020)

God. LXXI, br. 1179-80, str. 139-155

izvorni naučni rad

Primljen: 5.8.2020.

doi: https://doi.org/10.18485/iipe_mp.2020.71.1179_80.7

Aleksandar JAZIĆ

\title{
Promene u ciljevima Višegradske grupe nakon pristupanja Evropskoj uniji
}

\begin{abstract}
SAŽETAK
Po završetku Hladnog rata države Višegradske grupe transformisale su svoje političke i ekonomske sisteme kako bi pristupile Evropskoj uniji. Taj cilj su ostvarile 2004. godine. Donedavno su stavovi i politike ovih država bili usklađeni sa zvaničnim stavovima Unije. Međutim, u nastojanju da adekvatnije odgovori na nove spoljne i untrašnje izazove, kao što su sukob u Ukrajini i migrantska kriza, Brisel je formulisao stanovišta koje države Višegradske grupe nisu u potpunosti podržale. Zauzmanjem drugačijih pozicija u odnosu na institucije EU, ove države nastoje da zaštite svoje nacionalne interese i dobiju mogućnosti da u većoj meri utiču na kreiranje evropskih politika. Iako je to naišlo na protivljenje Brisela, pojedine članice EU podržale su mišljenja država Višegradske grupe. Na taj način ove države su podstakle formiranje novog bloka unutar EU. To im je omogućilo ne samo da se njihov glas više čuje, već je i dovelo u pitanje postojeću ravnotežu snaga u Uniji.

Ključne reči: Višegradska grupa, Evropska unija, Rusija, Ukrajina, Severnoatlantski savez, migrantska kriza, bezbednosna politika, međunarodni odnosi.
\end{abstract}

\section{Uvod}

Nakon završetka Hladnog rata i raspada Varšavskog pakta Poljska, Češka, Slovačka i Mađarska započele su transformaciju svojih političkih i

${ }^{1}$ Autor je naučni saradnik u Institutu za međunarodnu politiku i privredu, Beograd, e-mail: jazic@diplomacy.bg.ac.rs

Rad je nastao u okviru projekta „Srbija i izazovi u međunarodnim odnosima 2020. godine", koji finansira Ministarstvo prosvete, nauke i tehnološkog razvoja Republike Srbije, a realizuje Institut za međunarodnu politiku i privredu tokom 2020. godine. 
ekonomskih sistema. Važna oblast u ovoj transformaciji bila je promena $u$ sferi spoljnopolitičkih ciljeva. S obzirom na položaj ovih država nakon završetka Hladnog rata, kao i na stanje njihovih političkih i ekonomskih sistema, promene spoljnopolitičkih ciljeva predstavljale su veliki izazov. Naravno, u tom trenutku nije bilo izvesno koliko će proces tranzicije trajati i kakvi će biti njeni krajnji rezultati. Zato su Poljska, Češka, Slovačka i Mađarska kreirale zajednički oblik saradnje koji im je omogućio da lakše ostvare ciljeve u skladu sa njihovim interesima.

Na samitu premijera u Bratislavi, koji je održan 14. maja 1999. godine, definisani su ključni elementi, odnosno polja, saradnje između zemalja Višegradske grupe. Važna stavka u ovoj saradnji definisana na pomenutom samitu bili su spoljni poslovi. ${ }^{2} \mathrm{U}$ političkom smislu, Višegradska grupa predstavlja $\mathrm{i}$,fforum $u$ čijim okvirima zemlje članice mogu da izraze $\mathrm{i}$ koordinišu svoje stavove o širokom spektru pitanja od zajedničkog interesa. Zemlje članice ove inicijative često koordinišu svoje politike kako bi postigle bolje efekte, ali i ostvarile zadovoljavajuće ciljeve" ${ }^{3}{ }^{3}$

Dogovorena saradnja u oblastima obuhvaćenim pomenutim samitom otvorila je mogućnosti za brži unutrašnji razvoj država Višegradske grupe, ali i za njihov bolji položaj u međunarodnim odnosima. Usaglašenost oko spoljnopolitičkih ciljeva bila je posebno važna, jer su tada nastupile velike promene $\mathrm{u}$ međunarodnim odnosima koje su karakterisale brze promene $\mathrm{u}$ interesima velikih sila i jačanje raznih međunarodnih organizacija. Države Višegradske grupe su zajedničkim delovanjem lakše ostvarile postavljene ciljeve, pre svega prijem u Evropsku uniju (EU) i Severnoatlantski savez (North Atlantic Treaty Organization - NATO). Razvojem saradnje $u$ dogovorenim oblastima stvoreni su preduslovi za efikasnije rešavanje međusobnih problema država članica i problema koje jedna država članica ima sa ostalim susedima. Time su države članice Višegradske grupe doprinele stabilnosti u Centralnoj Evropi, što je u periodu nestabilnosti bilo veoma važno za ukupne međunarodne odnose.

Nakon 2004. godine od kada su države Višegradske grupe postale članice EU dosta toga se promenilo. Na području EU desile su se određene promene i krize prema kojima države Višegradske grupe nisu imale i nemaju identičan stav. Najznačajniji faktori, koji trenutno utiču na nastajanje razlika među ovim državama, su odnos EU prema Rusiji i migrantska kriza. Države

2 Videti: “Contents of Visegrad Cooperation 1999”, Contents of Visegrad Cooperation approved by the Prime Ministers' Summit Bratislava on 14th May 1999, The Visegrad Group, Internet: http:/ / www.visegradgroup.eu/cooperation/contents-of-visegrad$110412,26 / 01 / 2020$.

${ }^{3}$ András Simonyi, "Visegrad Cooperation: A 15-Year-Old Success Story", The Visegrad Group, Internet: http://www.visegradgroup.eu/the-visegrad-book/simonyi-andras-

140 visegrad, 29/01/2020. 
Višegradske grupe su i dalje sklone čvrstom usaglašavanju spoljnopolitičkih stavova u okviru ove inicijative, ali vremenom su se u njihovim stavovima $\mathrm{u}$ vezi sa ovim faktorima pojavile određene razlike.

\section{Odnosi sa Rusijom u svetlu krize u Ukrajini}

Deklaracijom iz Bratislave premijeri Poljske, Češke, Mađarske i Slovačke utvrdili su zajedničke stavove, između ostalog i u vezi sukoba u Ukrajini. Složili su se da trenutni bezbednosni izazovi zahtevaju čvršću regionalnu odbrambenu saradnju. Takođe, usaglasili su se da ti izazovi zahtevaju dalju koordinaciju njihovih stavova o aktuelnim bezbednosnim pitanjima važnim za NATO i EU. Založili su se za unapređenje saradnje u oblasti odbrane, na osnovu dugoročne vizije usvojene u martu 2014. Akcioni plan, koji je izrađen za vreme slovačkog predsedavanja, predstaviće konkretne korake ka tom cilju. Takođe će se nastaviti koordinacija nacionalnih stavova o aktuelnim pitanjima bezbednosti NATO i EU. Ovom deklaracijom zemlje Višegradske grupe potvrdile su posvećenost bezbednosti i stabilnosti u regionu Centralne Evrope. Potezi Rusije prema Ukrajini ocenjeni su kao nelegalni, posebno kada je reč o aneksiji Krima i Sevastopolja, ali i stalnim ruskim snažnim akcijama protiv Ukrajine. Države Višegradske grupe ove aktivnosti vide kao provokaciju duž istočne granice NATO. Njihov je stav da su ove provokacije značajno ugrozile bezbednost $\mathrm{u}$ regionu Centralne Evrope, što, prema njihovom mišljenju, otvara mogućnost novih sukoba među državama na granicama NATO. Države Višegradske grupe potvrdile su svoju posvećenost poštovanju međunarodnog prava, a posebno poštovanju suvereniteta i teritorijalnog integriteta svih država. Shodno tome, ove zemlje su se obavezale da $u$ narednom periodu usklađuju svoje stavove kako bi u najvećoj meri pružile podršku Ukrajini. U Deklaraciji je takođe istaknuto da ove države nastavljaju sa pripremama borbene grupe V4, koja će biti u pripravnosti, uz učešće Ukrajine. Ministri odbrane članica Višegradske grupe dobili su zadatak da istraže mogućnost formiranja stalne i fleksibilne borbene grupe V4 kako bi dali svoj doprinos NATO snagama i Snagama za brzo reagovanje EU, kao i operacijama upravljanja krizama. Istaknuta je namera da se poveća vidljivost, prepoznatljivost i interoperabilnost oružanih snaga ovih zemalja, kao i da se produbi njihova saradnja na polju obuke i vojnih vežbi. ${ }^{4}$

Evropska unija se oštro usprotivila ruskoj aneksiji Krima i kao prvi korak uvela je zabranu putovanja u martu 2014. godine i blokirala imovinu određenih osoba iz Rusije za koje je smatrala da su umešane u ovaj sukob.

\footnotetext{
${ }^{4}$ Videti: "Bratislava Declaration of Visegrad Group Heads of Government - Deepening V4 Defence Cooperation", Ministry of Foreign and European Affairs of the Slovak Republic, Internet: https://www.mzv.sk/documents/10182/51419/Bratislava+ Declaration+FINAL.pdf/8befd1e0-ae11-48a4-9e77-bf216a46c091, 31/01/2020.
} 
Zbog događaja u Ukrajini, EU je u julu 2014. godine uvela sankcije Rusiji, koje su dodatno pojačane u septembru iste godine. ${ }^{5}$

Tokom pregovora o sankcijama protiv Rusije češka vlada je pokušala da zaštiti interese svojih kompanija koje izvoze u Rusiju, posebno onih iz oblasti teške industrije. Mađarska i Slovačka bile su najviše zabrinute zbog efekata sankcija na bankarski sektor. Slovačka nije bila dovoljno jaka da blokira sankcionisanje podružnica ruskih banaka na svojoj teritoriji koje imaju snažnu poziciju na tržištu kapitala ove zemlje. Sa druge strane, Mađarska je imala najveći interes da izbegne ove sankcije jer bi to ugrozilo planirano proširenje nuklearne elektrane u Pakšu, čiju su izgradnju finansirale ruske kompanije.

Države Višegradske grupe, sa izuzetkom Poljske koja se u potpunosti složila sa ovim sankcijama, nisu nameravale da negativno utiču na jedinstvo EU u vezi sa pomenutim sankcijama. Preostale tri države ove inicijative izrazile su samo snažne sumnje u efikasnost ovih sankcija kada su u pitanju promene u ruskoj politici. U ekonomskom smislu Nemačka je najviše izgubila, ali se snažno zalagala za uvođenje sankcija Rusiji. Tako je Nemačka pokazala spremnost da preuzme vođstvo kada je reč o bezbednosti. Češka, Slovačka i Mađarska približile su se stavovima Nemačke o položaju NATO, dok je Poljska napravila određena odstupanja od njega. Poljska je bila više orijentisana na NATO kao organizaciju, pa je $u$ jednom trenutku zatražila vojnu podršku NATO u vezi sa krizom u Ukrajini. Poljska je smatrala da Mađarska na neki način sledi liniju Moskve, Slovačku je videla previše pragmatičnom, dok je politiku Češke doživljavala previše neusklađenom.

Na NATO samitu, u septembru 2014. godine, postignut je kompromis koji je zadovoljio interese dva bloka unutar ove organizacije, odnosno "starih" i istočnih članica. Rezultat je bio jačanje istočnog dela NATO. Početkom 2015. godine započelo je stvaranje Jedinice za integraciju NATO snaga (NATO Force Integration Unit - NFIU) na teritoriji nekoliko istočnih saveznika, odnosno Rumunije, Bugarske, Poljske i baltičkih država. Mađarska i Slovačka, kao takođe istočne članice NATO, zatražile su formiranje NFIU na svojoj teritoriji još u februaru 2015. godine. Uočljive su razlike u tumačenju pretnji koje bi mogle ugroziti bezbednost zemalja Višegradske grupe, kao i EU u celini. Češka, Slovačka i Mađarska podržale su stav Nemačke da ove aktivnosti jačaju bezbednost istočnih NATO članica, kao i da imaju potencijal odvraćanja Rusije.

Dakle, ove zemlje su napravile određenu distancu od Poljske, koja nije podržala stavove Nemačke u pogledu bezbednosti EU. Što se tiče zahteva za novim NATO bazama, stavovi zemalja Višegradske grupe značajno su se razlikovali. Poljska je aneksiju Krima videla kao direktnu pretnju i zatražila

${ }^{5}$ Videti: "EU sanctions against Russia over Ukraine crisis", European Union - newsroom, Internet: https://europa.eu/newsroom/highlights/special-coverage/eu-sanctions-

142 against-russia-over-ukraine-crisis_en, 01/02/2020. 
stalne NATO baze kako bi osigurala svoju bezbednost. Češka i Slovačka su jasno stavile do znanja da im aneksija Krima ne predstavlja direktnu pretnju. Mađarska nije iznela konkretan stav povodom dešavanja na Krimu. Još jedna tačka razmimoilaženja država Višegradske grupe u vezi sa krizom u Ukrajini bilo je pitanje moguće isporuke oružja ovoj državi. Poljska je verovala da bi isporuka oružja Ukrajini mogla biti korisna ako pregovori sa Rusijom propadnu. Međutim, ostale države Višegradske grupe, poput Nemačke, smatrale su da bi takav potez mogao dovesti do eskalacije sukoba u Ukrajini. ${ }^{6}$

Stav nekih drugih partnera država Višegradske grupe, poput Sjedinjenih Američkih Država (SAD), je takav da te zemlje ne pokazuju dovoljno usaglašenosti kada je reč o krizi u Ukrajini i sankcijama protiv Rusije. Kritika je upućena Mađarskoj, za koju se smatra da se kreće u odvojenom smeru od ostalih članica Višegradske grupe. Kao primer za to ističe se da je mađarski premijer Viktor Orban, uprkos svim pitanjima i problemima vezanim za Ukrajinu, tražio veću autonomiju mađarske manjine u ovoj zemlji. Kritikovana je i poseta Vladimira Putina Budimpešti. Međutim, konstatovano je da je Mađarska i dalje spremna da pošalje kontingent vojnika na istočne granice EU. Što se tiče Poljske, konstatovano je da postoji trgovinska razmena između ove zemlje i Rusije, kao i da je poljska diplomatija veoma pažljiva kada su u pitanju odnosi sa Rusijom. Smatra se da je to na neki način posledica različitog geopolitičkog položaja četiri članice Višegradske grupe. Drugim rečima, Poljska je, za razliku od ostalih članica, lakše dostupna mogućoj ruskoj agresiji. Zbog toga je Poljska upućena da vodi čvršću politiku kada je reč o krizi u Ukrajini i savesno sprovođenje sankcija protiv Rusije. Razmimoilaženja u okviru Višegradske grupe uticala su na opadanje njenog ugleda kao primera dobre tranzicije kroz međusobnu saradnju. Pre 2014. godine, odnosno pre nego što su razlike u stavovima postale jasno vidljive, države Višegradske grupe bile su prilično uspešne $u$ pretvaranju unutarregionalne u međuregionalnu saradnju. Drugim rečima, svojim primerom uspešno su proširili saradnju iz Centralne Evrope na druge delove Evrope, poput Zapadnog Balkana. ${ }^{7}$

Poljska je pokazala da su joj transatlantski odnosi najvažniji i ostala je uporna u podržavanju politika EU i NATO prema Rusiji. Takođe, ova zemlja je učinila napore u pravcu uspostavljanja energetske nezavisnosti od Rusije. S druge strane, Češka, Slovačka i Mađarska bile su umerenije prema Moskvi.

\footnotetext{
${ }^{6}$ Videti: Vendula Kotyzová, Vojtěch Bahenský and Jakub Kufčák, “Cooperation of CE countries in response to situation in Russian Federation and in Ukraine", Association for International Affairs, Prague, 2015, pp. 5-8.

${ }^{7}$ Videti: "Visegrad Group Divided on Russian Relations, but Maintaining Cooperation", Central European University, 29 April 2015, Internet: https:/ /www.ceu.edu/article/ 2015-04-29/visegrad-group-divided-russian-relations-maintaining-cooperation, $03 / 02 / 2020$.
} 
Nakon izbijanja krize u Ukrajini, početkom 2014. godine i učešća Rusije u njoj, vlade tri pomenute države pokazale su neodlučnost u podržavanju sankcija protiv ruskih zvaničnika. Najvažniji razlog bila je velika zavisnost od ruskih energenata. Ponekad se činilo da neki politički lideri zemalja Višegradske grupe Moskvu vide kao potencijalnu i korisnu protivtežu Briselu.

Ukrajinska kriza uticala je na Višegradsku grupu oslabivši Vajmarski trougao, uspostavljen 1991. godine kao mehanizam konsultacija između Nemačke, Francuske i Poljske. Poljska je ostala po strani kada su u pitanju diplomatska nastojanja da se pronađe mirno rešenje za ukrajinsku krizu. Sa druge strane, Francuska i Nemačka su kroz saradnju sa Moskvom aktivno nastojale da smire i stabilizuju situaciju na području Donbasa. Podele unutar Višegradske grupe videle su se odmah na početku sukoba u Ukrajini. Brojne države članice NATO pokrenule su programe podrške ukrajinskim oružanim snagama. Ipak, kada su u pitanju države Višegradske grupe, Poljska je obezbedila vojnu pomoć, dok su ostale države uglavnom obezbedile humanitarnu pomoć. U politici EU prema istočnim susedima Češkoj, Slovačkoj i Mađarskoj, odnosi sa Rusijom bili su važniji od odnosa sa Ukrajinom. Ipak, odnosi Češke, Slovačke i Mađarske sa Ukrajinom postepeno su oživljavali, pa se saradnja u okviru Višegradske grupe pokazala konstruktivnom. Preciznije, sve četiri zemlje Višegradske grupe ratifikovale su Sporazum o pridruživanju EU i Ukrajine, podržale proces liberalizacije viznog režima za ukrajinske građane i podržale implementaciju Sporazuma o dubokoj i sveobuhvatnoj zoni slobodne trgovine (Deep and Comprehensive Free Trade Agreement - DCFTA) između EU i Ukrajine.

Treba naglasiti da je od ulaska u EU 2004. godine jedan od glavnih ciljeva država Višegradske grupe aktivno učešće $u$ oblikovanju politike susedstva EU prema zemljama Istočne i Jugoistočne Evrope. Zaista, Višegradska grupa je vremenom postala važan format za jačanje veza između Ukrajine i EU. Tokom prethodnih godina Ukrajina je održavala sastanke u V4+ formatu na predsedničkom, premijerskom i ministarskom nivou.

$\mathrm{Na}$ primer, na zajedničkom sastanku država Višegradske grupe sa najvišim predstavnicima Ukrajine u Krinici u Poljskoj, septembra 2016. godine, formulisan je zajednički stav o nepovredivosti granica i teritorijalnom integritetu Ukrajine. Iako su neki predstavnici država Višegradske grupe dovodili u pitanje ekonomsku opravdanost sankcija protiv Rusije, do sada nijedna od četiri države nije blokirala produženje sankcija na nivou Saveta ministara EU. Takođe su dali punu podršku Sporazumu iz Minska kako bi se pronašlo mirno rešenje sukoba u Ukrajini. Treba napomenuti da je Ukrajina bila najveći korisnik sredstava Međunarodnog Višegradskog fonda (International Visegrad Fund - IVF) izvan Višegradske grupe. Između 2005. i 2016. Ukrajina je dobila ukupno 4,5 miliona evra bespovratnih sredstava $\mathrm{i}$ stipendija, što je u tom periodu iznosilo oko 6\% ukupnog IVF fonda.

144 Finansirani projekti odnosili su se na jačanje socijalnih kontakata između 
Ukrajine i država Višegradske grupe, kao i na podršku procesu ekonomskih reformi u Ukrajini. ${ }^{8}$

\section{Migrantska kriza}

Odnos institucija EU prema migracijama sa Bliskog istoka stvorio je krizu solidarnosti. Za sada se članice EU ne slažu oko sistema koji bi, prema individualnim kapacitetima, među njima delio odgovornost $\mathrm{u}$ vezi sa prijemom migranata. I dalje postoje razmirice oko toga koja članica treba da prihvati i smesti migrante koji stignu na teritoriju EU. Države članice na jugu EU traže usvajanje i poštovanje kvota za preseljenje i veću podeljenu odgovornost za prihvat migranata. Međutim, države članice Višegradske grupe ne pokazuju spremnost da podrže bilo koji oblik mehanizma solidarnosti i podele kvota za prihvat migranata. Države na severu i zapadu EU ističu otvorenost prema ograničenom preseljenju, ${ }^{9}$ ali i dalje veruju da treba zaustaviti. U skladu s tim, Evropska komisija je počela da podstiče reforme koje bi omogućile pronalaženje "sigurnih trećih zemalja” koje se nalaze u susedstvu država iz kojih dolaze migranti. EU je pokušala da utiče na solidarnost sa migrantima, ne samo među svojim članicama, već i šire. $U$ decembru 2018. godine 152 zemlje su potpisale rezoluciju Ujedinjenih nacija (UN) pod nazivom "Globalni sporazum za sigurnu, urednu i redovnu migraciju" (Global Compact for Safe, Orderly and Regular Migration). ${ }^{10}$ Ipak, pored SAD, nijedna od država članica Višegradske grupe nije potpisala ovaj sporazum. ${ }^{11}$

Migrantska kriza pokazala je postojanje dubokih neslaganja unutar EU. To je bilo posebno vidljivo kada je Evropska komisija 2015. godine razvila plan o šemi preseljenja. Da bi se podelila odgovornost, osmišljen je mehanizam za premeštanje migranata iz jedne države članice u drugu. Broj migranata koje bi država trebalo da prihvati meren je na osnovu nekoliko kriterijuma, kao što su broj stanovnika i BDP. Države Višegradske grupe suprotstavile su se planu i zbog toga su kritikovane da ne pokazuju dovoljno solidarnosti. Migrantska kriza pokazala je da je EU još na putu prihvatanja i usaglašavanja različitih mišljenja, čak i ideologija, među svojim članicama.

Dugo nakon pristupanja zemlje Višegradske grupe igrale su manju ulogu u EU. Nakon odbacivanja plana EU za preseljenje migranata, ove države

\footnotetext{
${ }^{8}$ Videti: Janusz Bugasiki, "The Visegrad Saga: Achievements, Shortcomings, Contradictions", Foreign Policy Review, Vol. 10, 2017, pp. 14-16.

${ }^{9}$ Radi se o sistemu kvota koji EU primenjuje prilikom prijema migranata.

${ }^{10} \mathrm{O}$ navedenom dokumentu videti detaljnije: "Resolution adopted by the General Assembly on 19 December 2018", United Nations, A/RES/73/195, 11 January 2019.

${ }^{11}$ Videti: Shoshana Fine, "All at sea: Europe's crisis of solidarity on migration", European Council on Foreign Affairs, October 2019, pp. 2-3.
} 
identifikovane su kao neko ko nije spreman da usklađuje svoje zakonodavstvo sa propisima i zajedničkom politikom EU. Ove države postavile su se kao protivteža savremenoj politici Brisela. Migraciona kriza otkrila je i unutarevropski sukob između država Višegradske grupe i EU. Razlog su nespojiva očekivanja između ovih država i EU, pa je sukob bio logična posledica.

Države Višegradske grupe trenutno svoje članstvo u EU doživljavaju kao drugorazredno, pa često ističu da se ono što im je predstavljeno pre pristupanja veoma razlikuje u praksi. To dovodi do porasta nezadovoljstva obe strane. Osećaj inferiornosti i različitosti država Višegradske grupe, s razlogom ili ne, utiče na njihove stavove na nivou EU. Takođe, ovakva percepcija sopstvenog položaja utiče i na njihovo ponašanje $u$ spoljnoj politici. Time se može ujedno objasniti i kritički nastrojeno ponašanje država Višegradske grupe, a najbolji primer je upravo pitanje migracija. Države Višegradske grupe bile su nezainteresovane ili su ignorisale ishod pregovora o šemi preseljenja migranata, koje su ministri unutrašnjih poslova EU pokrenuli u septembru 2015. godine. Slovačka i Češka su, bar u tom trenutku, pokazale spremnost da prihvate određen broj izbeglica, dok su Poljska i Mađarska u potpunosti odbile da učestvuju u planu. Tako su zemlje Višegradske grupe povećale svoju popularnost među članicama EU koje se protive prihvatanju migranata, ali su istovremeno stvorile negativnu sliku u institucijama EU. ${ }^{12}$ Kasnije su, međutim, Češka i Slovačka počele postepeno da revidiraju stavove $u$ vezi prihvata migranata.

Može se reći da je jedan od najvažnijih problema u vezi sa prijemom migranata napetost koja postoji između principa "solidarnosti” i principa „prvog ulaska”. ${ }^{13}$ Ovi principi i primat nekih od njih godinama su u središtu diskusija u EU. Države članice EU koje su pogranične insistiraju na usvajanju plana preraspodele migranata. Njihov je stav da će na taj način zahtevi podnosilaca za azil biti ravnomernije raspoređeni unutar EU. Ovo bi ublažilo trenutni pritisak na članice EU koje se nalaze na južnoevropskim granicama. Međutim, države Višegradske grupe - Poljska, Ceška, Slovačka i Mađarska jasno su stavile do znanja da ne prihvataju bilo kakve obavezne kvote za preraspodelu migranata iz jedne u drugu državu EU. Njihov stav je da moraju da zaštite svoja homogena društva od stranih pretnji, kao što su migracije. Među ostalim članicama EU postoje različita gledišta. Neke od njih dele stavove država Višegradske grupe. Pored predloga za reforme, ove države zajednički pojačavaju pritisak u vezi dogovora oko Zajedničkog evropskog

${ }^{12}$ Videti: Birgit Schölz, "Misunderstanding, conflict and divisions between the Visegrad Group and the European Union - an analytical discourse beyond the public", CES Working Papers, Vol. XI, Issue 1, pp. 22-28.

${ }^{13}$ Princip prvog ulaska regulisan je takozvanim Dablinskim propisima od kojih je najaktuelniji Dablin III o kojem detaljnije videti: "The implementation of the Dublin III

146 Regulation in 2018", European Council on Refugees and Exiles, Brussels, March 2019. 
sistema azila (Common European Asylum System - CEAS). ${ }^{14}$ Ovo postepeno razvija snažnu podelu unutar EU u pogledu sistema koji će regulisati migracije.

Trenutno su Austrija, Italija i Mađarska na istoj strani i pokušavaju da promene plan prihvata migranata ili spreče migraciju. Austrija nastoji da spreči ilegalne migracije, odnosno ponavljanje situacije iz 2015. godine kada je porast zahteva za prijem u ovu državu bio oko 240 procenata. To pokazuje da je došlo do razvoja saradnje između država Višegradske grupe i drugih zemalja EU, odnosno da će njihovi stavovi imati snažniji uticaj unutar EU. Nakon formiranja nove vlade u Italiji, koja ima desničarski karakter, ova osovina u EU je dodatno ojačala. Nova italijanska vlada je od početka počela sa pokušajima da reformiše migracionu politiku u EU, uz snažnu saradnju sa Mađarskom. Prema rečima njenih zvaničnika, Italija ne želi da bude posmatrana kao „,izbeglički kamp Evrope”. Nakon toga, ovaj stav se pokazao u praksi kada je Italija odbila da brod sa migrantima pristane u jednoj od italijanskih luka, a kasnije su izneti stavovi da će se takva politika nastaviti. U poređenju sa drugim državama koje žele da reformišu migracionu politiku EU, Grčka ima umereniji stav. Razlog je, na prvom mestu, oporavak od finansijske krize, a na drugom spor koji je donedavno postojao sa Bivšom Jugoslovenskom Republikom Makedonijom oko promene imena te države, koja se sada zvanično naziva Republika Severna Makedonija. Trenutni prioritet Grčke je postizanje kompromisa o evropskoj šemi preraspodele azila kako bi se smanjio teret koji Grčka, kao pogranična država EU, snosi. Što se tiče bliže saradnje Italije, Austrije i država Višegradske grupe, osnovno pitanje je da li će ta saradnja biti samo privremeni savez ili će se pretvoriti u trajnu i snažnu vezu. Trenutno, u njihovim odnosima interesi nisu u potpunosti usklađeni. Italija traži solidarnost od Austrije i država Višegradske grupe, ali nije naišla na pozitivan odgovor. Kao rezultat, Italija je pooštrila svoju poziciju i promenila svoj nekadašnji zahtev za solidarnošću $\mathrm{u}$ jasan stav da više ne želi da prihvata migrante. Time se, u stvari, Italija u potpunosti približila državama Višegradske grupe, što je opet ojačalo položaj država ove inicijative. Na osnovu prethodnih razgovora unutar EU, broj stanovnika i ukupni BDP bila bi dva osnovna kriterijuma u određivanju broja migranata koje bi neka članica trebalo da prihvati. Međutim, ovi kriterijumi ponovo stvaraju gore pomenutu podelu unutar EU, između država koje insistiraju na solidarnosti i država koje odbijaju bilo kakve kvote za prijem migranata. Pored članica Višegradske grupe, Austrije i Italije, u Sloveniji su takođe nedavno ojačale snage sa snažnim antimigrantskim stavom. Jačanje ove grupe država znači snažniju podršku pooštravanju i jačanju granične kontrole i okretanju takozvanom spoljnom azilu (outsourcing asylum) $\cdot{ }^{15}$ Druga

${ }^{14} \mathrm{O}$ Zajedničkom evropskom sistemu azila videti detaljnije: “A Common European Asylum System", Publications Office of the European Union, Luxembourg, 2014.

${ }^{15}$ Spoljni azil, koji se ponekad naziva i prenošenje azila, je vrsta migracione politike koju vode države EU i sastoji se od premeštanja prijema i smeštaja tražilaca azila i obrade 
opcija koja se razmatra je osnivanja kampova za migrante izvan EU, ali na evropskom kontinentu, ali nije jasno da li se radi o privremenom ili dugotrajnom prihvatu. Na tome posebno insistira Austrija, ali je teško pronaći treću zemlju u Evropi koja bi preuzela ovu ulogu. Ovaj koncept izaziva zabrinutost u EU zbog mogućih kršenja ljudskih prava. Države Višegradske grupe i Italija trenutno su spremne da podrže ovu ideju. Treća zamisao je osnivanje evropskih pritvorskih centara, koje su već uvele Francuska i Španija. Plan je da izbeglice i migranti koji su već ušli u EU budu naknadno poslati u druge države članice. Trenutne političke prilike u EU prepreka su za realizaciju ove ideje, posebno zato što ona sadrži i princip dobrovoljnosti. Holandija je, na primer, izrazila zabrinutost zbog ovog koncepta i smatra da treba tražiti zajedničko evropsko rešenje, koje podrazumeva efikasno upravljanje spoljnim granicama EU. Ovaj koncept podrazumeva i podelu kvota za prijem, pa ne treba očekivati podršku Italije, Austrije i država Višegradske grupe, jer im je ključni prioritet potpuna kontrola sopstvenih granica i sprečavanje migranata da uopšte uđu u EU. ${ }^{16}$ Ostaje pitanje kako će se problem sa migrantima rešiti, jer će se države koje se protive prijemu usprotiviti bilo kakvim planovima koji uključuju obavezne mehanizme kvota.

\section{Odnosi sa Briselom}

Države Višegradske grupe stoje na čelu dva naizgled suprotstavljena unutarevropska pokreta, za čije će usaglašavanje biti potrebno vreme. Radi se o pokretima za nacionalni suverenitet i/ili za asimetričnu integraciju. Vlade nekih država Višegradske grupe tvrde da brane nacionalni suverenitet od slabljenja i asimilacije u okviru EU. Sa druge strane, vlade istih država protive se da budu na sekundarnim pozicijama u procesu dublje integracije među članicama EU. Intenzivnija integracija pojedinih zemalja unutar EU učinila bi ih politički izolovanim i potencijalno ekonomski siromašnijim.

Politika odbrane suvereniteta nekih država članica širom EU pretvorila se $u$ snažan poziv političarima i strankama koje se suprotstavljaju „centralističkoj” EU koja određuje ekonomsku, kulturnu i socijalnu politiku svake države članice. Jedno uporište ovog otpora su male države EU koje su tokom svoje istorije bile žrtve stranog imperijalizma i kulturne asimilacije. Drugo uporište su široki slojevi stanovništva u nekim državama EU koji

njihovog zahteva za azil na mesta blizu granice EU ili u države koje nisu članice. Radi se o državama iz kojih tražioci azila potiču ili kroz koje prolaze.

${ }^{16}$ Videti: Willemijn Tiekstra, "The Future of the European Migration System: unlikely partners?", Strategic Monitoring 2018, Clingendael - the Netherlands Institute of

148 International Relations, July 2018, pp. 1-6. 
pokazuju strah zbog sve većih ekonomskih nejednakosti u svojim državama, što je dodatno podstaknuto jačanjem „liberalnih" elita.

Vlade u Varšavi i Budimpešti sebe vide kao uporišta socijalne i kulturne „kontrarevolucije“ protiv liberalizma i sekularizma u EU. Ovo partnerstvo je obostrano korisno, jer može blokirati predloge EU. Jedan od glavnih pokretača nacionalnog otpora u Poljskoj i Mađarskoj, ali i u nekim drugim zemljama, je priliv migranata u EU, što je detaljnije objašnjeno u prethodnim delovima teksta. Drugi razlog za kulturni i politički evroskepticizam zemalja Višegradske grupe proizilazi iz njihove zabrinutosti zbog predloga za proces integracije u EU u dve ili više brzina. Kao rezultat toga, vlade država Višegradske grupe često teže uspostavljanju ravnoteže u EU na vrlo kontradiktoran način. S jedne strane, oni se protive federalizaciji EU, a s druge strane, protive se bilo kakvom slabljenju postojećih međudržavnih veza insistiranjem na opstanku jedinstvenog tržišta. Model koji na neki način promoviše jedinstvo EU u pitanjima koja su im od vitalnog značaja, poput ekonomskog razvoja i zaštite granica. Međutim, čak i kada je reč o ovom modelu, zemlje Višegradske grupe izbegavaju čvršće fiskalne i političke integracije koje predlažu neke starije članice EU. Problem koji se javlja donekle je paradoksalan, odnosno ako bi se smanjila snaga nadnacionalnih institucija EU, pregovaračka pozicija svake zemlje Višegradske grupe u EU bi oslabila.

Osnovni problem je što su četiri države Višegradske grupe nedovoljno jake da utiču na odluke Nemačke, Francuske, Italije ili drugih država EU koje su dovoljno snažne da traže Uniju koja je politički i institucionalno integrisanija. Francuska je, na primer, glavni promoter ideje o Evropi sa više brzina. Za ovu državu Evropa sa više brzina je realnost i insistira na tome da članice EU koje teže čvršćoj integraciji ne treba da pritiskaju ostale članice da se kreću napred ako to ne žele. Jasno je da bi time države Višegradske grupe mogle da budu isključene iz procesa. Francuski prioritet $u$ tom smislu je jačanje i integracija evrozone. Time bi se mogao oslabiti položaj država Višegradske grupe, naravno manje u slučaju Slovačke, uz pojavu mogućnosti za međusobne podele. Slovačka je jedina država Višegradske grupe koja je usvojila evro, a ostale tri ne planiraju da usvoje zajedničku valutu, uprkos ugovorima o pristupanju EU koji to podrazumevaju. ${ }^{17}$

Trenutno, kao države članice EU, države Višegradske grupe su aktivne u evropskim poslovima i imaju snagu da predstavljaju lobi ili uticajnu grupu u EU. Snaga njihovog glasa do određene mere će uticati na programe i politiku EU. Ako države Višegradske grupe dobiju podršku članica koje su se kasnije pridružile EU, poput Rumunije, Bugarske i Hrvatske, njihov uticaj u evropskoj politici biće dodatno ojačan. Ako se pogleda podela glasačkih prava u Savetu Evropske unije, države Višegradske grupe nisu zanemarljive.

${ }^{17}$ Videti: Janusz Bugasiki, op. cit., pp. 10-13. 
Naime, Poljska ima 27, Slovačka 7, a Češka i Mađarska po 12 glasova, odnosno zajedno imaju 58 glasova. To je jednako glasovima Francuske i Nemačke od kojih svaka ima 29 glasova, a zajedno 58 glasova. Kada Savet Evropske unije donosi odluke kvalifikovanom većinom, glasovi država Višegradske grupe imaju veliku snagu. Treba priznati da države Višegradske grupe imaju značajan politički uticaj u EU i mogu da deluju kao protivteža dominaciji Nemačke i Francuske. Od svih država Višegradske grupe, kao što je već rečeno, evrozoni je pristupila samo Slovačka. Mađarska je jasno stavila do znanja da još nije definisala vremenski period za ulazak u evrozonu. Tokom 2015. godine vlada Češke razmatrala je plan o uvođenja evra do 2020. godine, ali nije došlo do usaglašavanja oko jasnog datuma za ovaj korak. U međuvremenu, političke promene u Češkoj rezultirale su protivljenjem da se uvede evro kao zvanična valuta. Slučaj sa Poljskom je sličan. U cilju jačanja pozicije ove države u EU, krajem 2014. godine, tadašnja vlada Poljske je kratak vremenski period raspravljala o tom pitanju i pokušala da ubrza ulazak ove države u evrozonu. Ipak, nije bilo saglasnosti oko bilo kog realističnog plana oko uvođenja evra. Nova vlast u Poljskoj, formirana 2015. godine, promenila je kurs i usprotivila se uvođenju evra. Podeljenost $u$ vezi sa evrozonom, odnosno činjenica da je jedna država Višegradske grupe u evrozoni, a tri van nje, može predstavljati problem za ovu inicijativu u budućnosti. Konkretnije, u ovakvoj situaciji je teško da države Višegradske grupe formiraju zajednički stav u vezi sa ekonomskim poslovima u okviru EU. Time se u određenoj meri slabi pregovaračka moć država Višegradske grupe $\mathrm{u}$ institucijama EU. ${ }^{18}$

Jedan od najvažnijih ciljeva država Višegradske grupe jeste da zauzmu ozbiljnu poziciju u EU. Snažan glas država Višegradske grupe u EU treba da odražava želje država Centralne Evrope i ukaže na polja politike koja su suštinski važna za te države u evropskoj politici. Kao što je već naglašeno, cilj država Višegradske grupe je da se u okviru institucija EU i međusobnim usaglašavanjem stavova izbore sa uzrocima prisilne migracije. Takođe, nastoje da ojačaju graničnu kontrolu, ali i da istovremeno spreče eroziju tradicionalnih evropskih principa slobodnog kretanja radne snage koja potiče iz Šengenskog sistema.

Što se tiče budućeg razvoja evropske politike, države Višegradske grupe fokusiraju se na pitanja u kojima mogu doprineti konstruktivnijem dijalogu. Zbog toga, države Višegradske grupe često ne ističu teme o kojima postoje različita mišljenja, već identifikuju i promovišu teme za koje mogu naći zajednički interes.

U oblasti ekonomije prioritet država Višegradske grupe je da promovišu svoj interes tokom pregovora o narednom višegodišnjem budžetu EU za

${ }^{18}$ Videti: Kong Tianping, “The Role of Visegrad Group and its Prospect: An outsider's view", Foreign Policy Review, Vol. 10, 2017, pp. 59-60. 
period od 2021. do 2027. godine. Češka je u 2019. godini bila neto doprinositelj ${ }^{19}$ višegodišnjem budžetu EU. Poljska želi da sledi taj primer, jer EU ima ambiciozne ciljeve u oblasti inovacija i konkurentnosti, kao i bezbednosne politike i migracije. Države Višegradske grupe voljne su da urade sve što je neophodno u finansijskom smislu kako bi se podržali zajednički evropski projekti, jer još ima mogućnosti za povećanje ekonomske konvergencije između država članica EU. Povećanje ekonomske konvergencije unutar EU je u interesu i zapadnih privatnih kompanija, jer bez nedavne kohezione podrške za region Centralne Evrope njihova direktna strana ulaganja ne mogu da pronađu svoje tržišne mogućnosti, i povremeno će se prelivati prema istočnim susedima EU. Države Višegradske grupe smatraju da je povećanje kupovne moći njihovih građana najvažniji uslov za prodaju robe proizvedene u državama EU.

Države Višegradske grupe žele pojednostavljivanje politike kohezije i da novi propisi budu zaštićeni od nekih značajnih promena u budućnosti. Ove države smatraju da su inicijative o budućnosti EU važne, ali insistiraju na tome da je najvažniji zadatak svih država članica da pokažu verodostojnost i doslednost. Zato je stav država Višegradske grupe da EU mora da poštuje sopstvene obaveze utvrđene Lisabonskim sporazumom iz 2009. godine i da ne ubrzava reformske procese pojedinačnim odlukama. Time se narušavaju tradicionalne evropske vrednosti zasnovane na pristanku svih članica EU kao suverenih država. Što se tiče prijema novih država u EU, države Višegradske grupe snažno podržavaju prijem Srbije, Bosne i Hercegovine, Makedonije i Crne Gore. Sličan argument države Višegradske grupe iznose i u vezi slobodnog kretanja radne snage, pa ove države imaju nameru da odbrane Šengenski sistem kroz jačanje zaštite granica. ${ }^{20}$

Značajno jačanje saradnje država Višegradske grupe na ključnim pitanjima EU može se primetiti od 2009. do 2011. godine. Važan trenutak bila je gasna kriza iz 2009. kada su države Višegradske grupe koristile fondove EU i regulatorni okvir Evropske komisije za izgradnju neophodne infrastrukture, čime su ugrozile položaj ruskog Gazproma kao jedinog snabdevača gasom. Vlade država Višegradske grupe postale su snažan činilac oblikovanja politike i nisu više samo učesnik i sprovodilac raznih politika EU. Primer političke snage ovih država je postizanje uravnoteženog kompromisa u vezi sa klimatskim paketom EU u oktobru 2014. godine. Umesto da blokiraju čitav proces, države Višegradske grupe i druge države kao što su Rumunija i Bugarska, postavile su zajednički skup zahteva za konačni dogovor. Koristeći zahtev da se postigne konsenzus među državama članicama, uspeli su da obezbede bolje uslove za buduće nivoe

${ }^{19}$ Neto doprinositelj je država koja daje više u budžet EU, nego što iz njega dobija.

${ }^{20}$ Videti: Péter Stepper, "Visegrad Cooperation beyond the Polish and during the Hungarian V4 Presidency", Foreign Policy Review, Vol. 10, 2017, pp. 94-96. 
smanjenja emisije za svoje industrije. U pripremnim fazama samita EU u Bratislavi, 16. septembra 2016. godine, prejak pristup ${ }^{21}$ institucijama EU koje su predstavile Poljska i Mađarska izazvao je zabrinutost Češke i Slovačke. Poslednje dve države nisu želele da podrže radikalne poteze koji bi izazvali još razdora i sukoba među liderima EU. Na kraju su države Višegradske grupe uspele da dobiju ustupke od svojih EU partnera za migracionu politiku. U Bratislavi je usvojen koncept "fleksibilne solidarnosti” koji omogućava državama članicama EU da na dobrovoljnoj osnovi odlučuju o konkretnim oblicima doprinosa odgovoru EU, uzimajući u obzir njihovo iskustvo i kapacitete. Države Višegradske grupe su time dobile zadatak da usvojeni koncept ispune aktivnostima u praksi. ${ }^{22}$

\section{Zaključak}

Funkcionisanje Višegradske grupe odvija se na redovnoj osnovi, ali se ipak među njenim članicama u poslednjem periodu primećuje napetost i nesklad u funkcionisanju ove inicijative. To je možda i očekivano s obzirom na to da je od ostvarenja najvažnijeg cilja, odnosno od uključivanja u EU, prošlo skoro dve decenije. Svaka država Višegradske grupe je nakon prijema $\mathrm{u}$ članstvo počela da razmišlja o narednim koracima u pravcu sopstvenog razvoja. Zato je i došlo do određenih razmimoilaženja. Ipak, kao deo jedne inicijative koja je opstala, države Višegradske grupe i dalje shvataju značaj zajedničkog nastupa u odnosu sa drugim državama. Zato su vremenom ove države došle do zaključka koji su njihovi zajednički interesi i ciljevi koji proizilaze iz oblasti njihove saradnje. Trenutno postoje tri oblasti u kojima ove države nastoje da ostvare zajedničke ciljeve, a to su energetska politika, digitalizacija i bezbednost.

Kada je reč o energetici, cilj država Višegradske grupe je isti kao i cilj EU, odnosno stvaranje jedinstvenog evropskog energetskog tržišta i smanjenje potencijalnih spoljnih uticaja. Na osnovu prethodnih delova teksta nameće se zaključak da države članice EU žele da smanje zavisnost od snabdevanja energentima iz Rusije, čime bi se EU nametnula kao ravnopravniji partner $u$ odnosima sa ovom državom. To je posebno važno za države Višegradske grupe jer se Rusija nalazi u njihovom bližem okruženju. Može se reći da se cilj svodi na pronalaženje najjeftinije alternative za, na primer, uvoz gasa iz Rusije. Ipak, to ne znači potpuno isključivanje Rusije, već da se ova država podstakne da ostane konkurentna i da prihvati zahtev EU da se primenjuje

${ }^{21}$ Poljska je želela da na samitu iznese predloge koji se tiču osetljivih pitanja u vezi sa funkcionisanjem EU, kao što su: institucionalna ravnoteža u Briselu, politički program EU i odnosi između institucija EU i država članica.

${ }^{22}$ Videti: Milan Nič, “The Visegrád Group in the EU: 2016 as a turning-point?”, European

152 View, Vol. 15, 2016, pp. 285-287. 
Treći energetski paket. ${ }^{23}$ Prioritet za države Višegradske države u tom smislu je da smanji potrošnju fosilnih goriva i poveća korišćenje nuklearne energije, ali u skladu sa ekološkim ciljevima koje je EU zacrtala do 2030. godine. Države Višegradske grupe suočene su i sa problemom zastarele elektro i gasne infrastrukture. To ih onemogućava u povećanju proizvodnje, jer očekuju da će se u narednom periodu povećati potrošnja gasa i električne energije. Zato planiraju da ove probleme reše većim oslanjanjem na nuklearnu energiju. ${ }^{24}$

Drugi važan cilj država Višegradske grupe je da ne dozvole zaostajanje njihovih industrijskih kapaciteta usled nedavne digitalne revolucije. Zato su postepeno počeli da transformišu svoje najvažnije privredne sektore kako bi se uklopili u nedavne inovacije. Prvi korak je formiranje jedinstvenog digitalnog tržišta među državama Višegradske grupe. Drugi korak je uključivanje modernih tehnoloških inovacija kako bi se povećala konkurentnost. Time ujedno ove države žele da promovišu interese Centralne Evrope u okviru strategije jedinstvenog digitalnog tržišta EU.

U oblasti odbrambene politike države Višegradske grupe žele da njihove vojske imaju pune kapacitete za učešće u međunarodnim misijama, u cilju doprinosa kolektivnoj sigurnosti u okviru NATO. S tim u vezi, ove države imaju nameru da povećaju budžete za odbranu. Za njih je to posebno bitno kako bi ojačale sposobnost odvraćanja u slučaju pretnji sa Istoka ili sa Juga. Takođe, u oblasti bezbednosti za države Višegradske grupe izuzetnu važnost ima jačanje policijskih snaga. Zato ove države zajednički rade na sprovođenju zakona i kontroli granica. To je i logično s obzirom na već pomenute probleme izazvane ilegalnim migracijama, ali i u slučaju epidemija i prirodnih katastrofa.

\section{Bibliografija}

"A Common European Asylum System", Publications Office of the European Union, Luxembourg, 2014.

Bratislava Declaration of Visegrad Group Heads of Government Deepening V4 Defence Cooperation", Ministry of Foreign and European Affairs of the Slovak Republic, Internet: https://www.mzv.sk/ documents/10182/51419/Bratislava+Declaration+FINAL.pdf/8befd1e0 -ae11-48a4-9e77-bf216a46c091, 31/01/2020.

${ }^{23}$ O Trećem energetskom paketu videti detaljnije: "Third energy package", European Commission, Internet: https:/ / ec.europa.eu/energy/topics/markets-and-consumers/ market-legislation/third-energy-package_en, 08/10/2020.

${ }^{24}$ Videti detaljnije: Andrej Nosko, Anita Orbán, Wojchiech Paczyński, Filip Čhernoch and Jakub Jaroš, "Energy Security", Slovak Atlantic Commission, Policy Paper, Bratislava, pp. 1-3. 
Bugasiki, Janusz, "The Visegrad Saga: Achievements, Shortcomings, Contradictions", Foreign Policy Review, Vol. 10, 2017.

"Contents of Visegrad Cooperation 1999", Contents of Visegrad Cooperation approved by the Prime Ministers' Summit Bratislava on 14th May 1999, The Visegrad Group, Internet: http://www.visegradgroup.eu/ cooperation/contents-of-visegrad-110412, 26/01/2020.

"EU sanctions against Russia over Ukraine crisis", European Union newsroom, Internet: https://europa.eu/newsroom/highlights/specialcoverage/eu-sanctions-against-russia-over-ukraine-crisis_en, $01 / 02 / 2020$.

Fine, Shoshana, "All at sea: Europe's crisis of solidarity on migration", European Council of Foreign Affairs, October 2019.

Kotyzová, Vendula, Bahenský, Vojtěch and Kufč́k, Jakub, “Cooperation of $\mathrm{CE}$ countries in response to situation in Russian Federation and in Ukraine", Association for International Affairs, Prague, 2015.

Nic, Milan, "The Visegrád Group in the EU: 2016 as a turning-point?", European View, Vol. 15, 2016.

Nosko, Andrej, Orbán, Anita, Paczyński, Wojchiech, FČhernoch, Filip and Jaroš, Jakub, "Energy Security”, Slovak Atlantic Commission, Policy Paper, Bratislava.

"Resolution adopted by the General Assembly on 19 December 2018", United Nations, A/RES/73/195, 11 January 2019.

Schölz, Birgit, "Misunderstanding, conflict and divisions between the Visegrad Group and the European Union - an analytical discourse beyond the public", CES Working Papers, Vol. XI, Issue 1.

Simonyi, András, "Visegrad Cooperation: A 15-Year-Old Success Story", The Visegrad Group, Internet: http:/ /www.visegradgroup.eu/the-visegradbook/simonyi-andras-visegrad, 29/01/2020.

Stepper, Péter, "Visegrad Cooperation beyond the Polish and during the Hungarian V4 Presidency", Foreign Policy Review, Vol. 10, 2017.

Tianping, Kong, "The Role of Visegrad Group and its Prospect: An outsider's view", Foreign Policy Review, Vol. 10, 2017.

Tiekstra, Willemijn, "The Future of the European Migration System: unlikely partners?", Strategic Monitoring 2018, Clingendael - the Netherlands Institute of International Relations, July 2018.

"The Implementation of the Dublin III Regulation in 2018", European Council on Refugees and Exiles, Brussels, March 2019.

"Third energy package", European Commission, Internet: https://ec.europa. eu/energy/topics/markets-and-consumers/market-legislation/thirdenergy-package_en, 08/10/2020. 
"Visegrad Group Divided on Russian Relations, but Maintaining Cooperation", Central European University, 29 April 2015, Internet: https:/ /www.ceu. edu/article/2015-04-29/visegrad-group-divided-russian-relationsmaintaining-cooperation, 03/02/2020.

\title{
CHANGES IN THE GOALS OF THE VISEGRAD GROUP AFTER ACCESSION TO THE EUROPEAN UNION
}

\begin{abstract}
After the end of the Cold War, the states of the Visegrad Group transformed their political and economic systems in order to join the European Union. They achieved that goal in 2004. Until recently, the positions and policies of these countries were in line with the official positions of the Union. However, to respond more adequately to new external and internal challenges, such as the conflict in Ukraine and the migrant crisis, Brussels has formulated positions that the Visegrad Group countries have not fully supported. By taking different positions in relation to the EU institutions, these countries try to protect their national interests and get opportunities to have a greater influence on the creation of European policies. Although this was opposed by Brussels, some EU members supported the opinions of the Visegrad Group countries. In that way, these countries encouraged the formation of a new block within the EU. This not only allowed them to have their voices heard more but also called into question the existing balance of power in the Union.

Keywords: Visegrad Group, European Union, Russia, Ukraine, North Atlantic Treaty Organization, the migrant crisis, security policy, international relations.
\end{abstract}

